\title{
PELATIHAN SEBUAH SOLUSI DALAM PEMBELAJARAN IPA TERPADU BAGI DOSEN IPA DI LINGKUNGAN PRODI PGMI
}

\author{
Budiyono Saputro \\ Dosen Sekolah Tinggi Agama Islam Negeri (STAIN) Salatiga
}

\begin{abstract}
Abstrak
Perubahan struktur kurikulum SD/MI sudah tentu mempengaruhi struktur kurikulum pada Lembaga Pendidikan Tenaga Kependidikan Agama Islam. Fakultas Tarbiyah dengan Prodi PGMI merupakan Prodi yang menghasilkan guru kelas pada Madrasah Ibtidaiyah (MI). Proses dan metode perkuliahan yang dilakukan oleh dosen pada PGMI pun menyesuaikan. Kurikulum pada mata kuliah IPA dan Pendidikan IPA serta Praktikum IPA adalah salah satu mata kuliah yang harus dikuasai dan diajarkan oleh dosen pada prodi PGMI. Program pembelajaran IPA dilaksanakan secara terpadu. Pada sisi lain latar belakang pendidikan dosen bukan sepenuhnya berlatar belakang pendidikan IPA. Hal tersebut dikarenakan pada Lembaga Tenaga Kependidikan, IPA diberikan dalam spesifikasi yang jelas yaitu: Pendidikan Biologi, Pendidikan Kimia dan Pendidikan Fisika. Pada Universitas bidang IPA terspesifikasi ilmu murni yaitu: Biologi, Kimia dan Fisika. Kenyataan dilapangan kualifikasi dosen adalah berlatar belakang pendidikan yang memiliki spesifikasi bidang Biologi, Pendidikan Biologi, Kimia, Pendidikan Kimia, Fisika, pendidikan Fisika serta Pendidikan IPA. Berdasarkan kualifikasi dan latar belakang pendidikan dosen tersebut, maka dalam pembelajaran dosen akan terfokus pada bidangnya masing-masing. Pembelajaran yang demikian bukan merupakan pembelajaran IPA secara terpadu. Dari fakta tersebut maka diperlukan peningkatan kualitas profesionalisme dosen di Lembaga Pendidikan Tenaga Kependidikan. Kualitas akademik dosen menjadi sangat penting dan menjadi tolak ukur dalam pendidikan pada suatu program studi.

Pelatihan merupakan salah satu program yang dapat dijadikan untuk mempertajam pengetahuan dan keterampilan bagi dosen. Program pelatihan diadakan dengan memfasilitasi dosen untuk peningkatan kualitas pengetahuannya agar output yang dihasilkan dalam lembaga pendidikan dapat memenuhi tuntutan stakeholder baik regional, nasional maupun internasional. Selain itu juga penyampaian materi, strategi pembelajaran dapat dicapai secara terpadu. Pembelajaran IPA terpadu akan lebih bermakna jika disertai dengan alat bantu, media dan metode yang kreatif dan inovatif. Pelatihan Pembelajaran IPA Terpadu pada Program PGMI merupakan solusi untuk memaksimalkan kemampuan dosen IPA yang berlatar belakang pendidikan
\end{abstract}


sarjana Pendidikan Biologi, Kimia dan Fisika serta Biologi murni, Kimia murni dan Fisika murni.

Kata Kunci: pelatihan, pembelajaran, IPA Terpadu

\section{A. Pendahuluan}

Dalam posisi sebagai "jantung" perguruan tinggi, dosen sangat menentukan mutu pendidikan dan lulusan yang dilahirkan perguruan tinggi tersebut, disamping secara umum kualitas perguruan tinggi itu sendiri. Jika para dosennya bermutu tinggi, maka kualitas perguruan tinggi tersebut juga akan tinggi, demikian pula sebaliknya. Sebaik apapun program pendidikan yang dicanangkan, apabila tidak didukung oleh para dosen bermutu tinggi, maka akan berakhir pada hasil yang tidak memuaskan. Hal itu karena untuk menjalankan program pendidikan yang baik diperlukan para dosen yang juga bermutu baik. Dengan memiliki dosen-dosen yang baik dan bermutu tinggi, perguruan tinggi dapat merumuskan program serta kurikulum termodern untuk menjamin lahirnya lulusan-lulusan yang berprestasi dan berkualitas istimewa. ${ }^{1}$

Di Indonesia pada jenjang pendidikan dasar dan menengah telah mengalami beberapa kali perubahan kurikulum, tahun 1984, 1994, 2004 dan tahun 2006. Kurikulum saat ini pada jenjang pendidikan dasar dan menengah berdasarkan KTSP (Kurikulum Tingkat Satuan Pendidikan). KTSP memberikan otonomi pada sekolah untuk mengelola dan menyesuaikan potensi yang dimiliki sekolah agar sekolah tersebut dapat meningkatkan mutu sesuai dengan kondisinya. Perubahan kurikulum ini tentunya menyebabkan perubahan struktur dan pola pembelajaran serta penyesuaian kualifikasi pendidikan dosen. Berdasarkan kerangka struktur kurikulum KTSP pada jenjang pendidikan dasar dan menengah, maka diperlukan proses pembelajaran terpadu bagi dosen untuk memenuhi standar pendidikan yang telah ditetapkan. Perubahan struktur kurikulum SD/MI sudah tentu mempengaruhi struktur kurikulum pada Lembaga Pendidikan Tenaga Kependidikan Agama Islam. Fakultas Tarbiyah dengan Prodi PGMI merupakan Prodi yang menghasilkan guru kelas pada MI. Proses dan metode perkuliahan yang dilakukan oleh dosen pada PGMI pun menyesuaikan. Kurikulum pada mata kuliah IPA dan pendidikan IPA serta praktikum IPA adalah salah satu mata kuliah yang harus dikuasai dan diajarkan oleh dosen pada prodi PGMI. Program pembelajaran IPA dilaksanakan secara terpadu. Pada sisi lain latar belakang pendidikan dosen bukan sepenuhnya berlatar belakang pendidikan IPA. Hal tersebut dikarenakan pada Lembaga Tenaga Kependidikan IPA diberikan dalam spesifikasi yang jelas yaitu: Pendidikan Biologi, Pendidikan Kimia dan Pendidikan Fisika. Pada universitas bidang IPA terspesifikasi ilmu

1 Barakat, Mohammad 'Adil (et. al.), al-Tathwir al-Mahniy li A'dla'i Hay'at al-Tadris, (Tunis: alMunazhzhamah al-'Arabiyah li al-Tarbiyah, 1998), hlm. 121 
murni yaitu: Biologi, Kimia dan Fisika. Kenyataan di lapangan kualifikasi dosen adalah berlatar belakang pendidikan yang memiliki spesifikasi bidang Biologi, Pendidikan Biologi, Kimia, Pendidikan Kimia, Fisika, Pendidikan Fisika serta Pendidikan IPA. Berdasarkan kualifikasi dan latar belakang pendidikan dosen tersebut, maka dalam pembelajaran dosen akan terfokus pada bidangnya masing-masing. Pembelajaran yang demikian bukan merupakan pembelajaran IPA secara terpadu. Dari fakta tersebut maka diperlukan peningkatan kualitas profesionalisme dosen di Lembaga Pendidikan Tenaga Kependidikan. Kualitas akademik dosen menjadi sangat penting dan menjadi tolak ukur dalam pendidikan pada suatu program studi.

Dalam pembelajaran IPA dewasa ini banyak timbul permasalahan dalam aplikasi pembelajaran di kelas. Salah satu masalah yang cukup mendesak untuk dicari solusinya terutama dengan menggunakan inovasi pendekatan sistem adalah pembelajaran Sains secara terpadu (pendidikan Sains). Aplikasi dari pembelajaran ini biasanya dalam pembelajaran berbasis lingkungan dan lain sebagainya. Pendidikan Sains terpadu (science for all) lahir karena adanya ketimpangan skema berpikir holistik terintegrasi (menyeluruh dan terpadu) mengenai Sains. Dulu Sains dipelajari secara terpisah sesuai bidang kajian Sainsnya, seperti bidang kajian Fisika, Kimia, dan Biologi. Kemunculan pendidikan Sains juga menimbulkan masalah baru, dulu kita dapat memandang suatu kajian konsep secara mendalam baik secara bidang kajian Fisika, Kimia, maupun Biologi. Tetapi sekarang dengan adanya pendidikan Sains terpadu ini, pembelajaran dalam penerapan konsep yang ditinjau dari ketiga aspek kajian cenderung dangkal. Sehingga, pembelajaran terkesan setengah-setengah dalam penerapan konsep-konsepnya di lapangan. Siswa juga mendapatkan pembelajaran Sains yang tidak maksimal dan kurang mengenai sasaran dalam pengembangan kognitif, afektif, dan psikomotor.

\section{B. Tujuan Pembelajaran IPA Terpadu}

\section{Meningkatkan Efisiensi dan Efektivitas Pembelajaran}

Dalam Standar Kompetensi dan Kompetensi Dasar yang harus dicapai peserta didik masih dalam lingkup disiplin ilmu Fisika, Kimia, dan Biologi. Banyak ahli yang menyatakan pembelajaran IPA yang disajikan secara disiplin keilmuan dianggap terlalu dini bagi anak usia 7-14 tahun, karena anak pada usia ini masih dalam transisi dari tingkat berpikir operasional konkret ke berpikir abstrak. Lagi pula, anak melihat dunia sekitarnya masih secara holistik. Atas dasar itu, pembelajaran IPA hendaknya disajikan dalam bentuk yang utuh dan tidak parsial. Di samping itu pembelajaran yang disajikan terpisah-pisah dalam Fisika, Biologi, Kimia, dan bumi-alam semesta memungkinkan adanya tumpang tindih dan pengulangan, sehingga membutuhkan waktu dan energi yang lebih banyak, serta membosankan bagi peserta didik. Apabila konsep yang tumpang tindih dan pengulangan dapat dipadukan, maka pembelajaran akan lebih efisien dan efektif. 
Keterpaduan mata pelajaran dapat mendorong guru untuk mengembangkan kreativitas tinggi karena adanya tuntutan untuk memahami keterkaitan antara satu materi dengan materi yang lain. Guru dituntut memiliki kecermatan, kemampuan analitik, dan kemampuan kategorik agar dapat memahami keterkaitan atau kesamaan materi maupun metodologi.

\section{Meningkatkan Minat dan Motivasi}

Pembelajaran terpadu memberikan peluang bagi guru untuk mengembangkan situasi pembelajaan yang utuh, menyeluruh, dinamis, dan bermakna sesuai dengan harapan dan kemampuan guru, serta kebutuhan dan kesiapan peserta didik. Dalam hal ini, pembelajaran terpadu memberikan peluang bagi pengembangan ilmu pengetahuan yang berkaitan dengan tema yang disampaikan. Pembelajaran IPA Terpadu dapat mempermudah dan memotivasi peserta didik untuk mengenal, menerima, menyerap, dan memahami keterkaitan atau hubungan antara konsep pengetahuan dan nilai atau tindakan yang termuat dalam tema tersebut. Dengan model pembelajaran yang terpadu dan sesuai dengan kehidupan sehari-hari, peserta didik digiring untuk berpikir luas dan mendalam untuk menangkap dan memahami hubungan konseptual yang disajikan guru. Selanjutnya peserta didik akan terbiasa berpikir terarah, teratur, utuh, menyeluruh, sistemik, dan analitik. Peserta didik akan lebih termotivasi dalam belajar apabila mereka merasa bahwa pembelajaran itu bermakna baginya, dan apabila mereka berhasil menerapkan apa yang telah dipelajarinya.

\section{Beberapa Kompetensi Dasar dapat Dicapai Sekaligus}

Model pembelajaran IPA terpadu dapat menghemat waktu, tenaga, dan sarana, serta biaya karena pembelajaran beberapa kompetensi dasar dapat diajarkan sekaligus. Di samping itu, pembelajaran terpadu juga menyederhanakan langkah-langkah pembelajaran. Hal ini terjadi karena adanya proses pemaduan dan penyatuan sejumlah standar kompetensi, kompetensi dasar, dan langkah pembelajaran yang dipandang memiliki kesamaan atau keterkaitan (Puskur Balitbang Depdiknas).

\section{Hakikat Pembelajaran IPA terpadu}

Pembelajaran IPA terpadu merupakan salah satu model implementasi kurikulum yang dianjurkan untuk diaplikasikan pada semua jenjang pendidikan, mulai dari tingkat Sekolah Dasar/Madrasah Ibtidaiyah (SD/MI) sampai dengan Sekolah Menengah Atas/Madrasah Aliyah (Tim Widyaiswara LPMP Jawa Tengah, 2008). Model pembelajaran ini pada hakikatnya merupakan suatu pendekatan pembelajaran yang memungkinkan siswa baik secara individual maupun kelompok aktif mencari, menggali, dan menemukan 
konsep serta prinsip secara holistik dan otentik (Depdiknas, 2004b). Pembelajaran IPA terpadu merupakan model implementasi kurikulum, yang mencoba memadukan beberapa kompetensi dasar yang dikemas dan disajikan dalam satu kegiatan pembelajaran dalam suatu topik/tema tertentu (Bundu, 2006).

Salah satu kunci pembelajaran terpadu adalah menyediakan lingkungan belajar yang menempatkan peserta didik untuk mendapatkan pengalaman belajar yang dapat menghubungkaitkan konsep-konsep dari berbagai kajian (Depdiknas, 2004b). Pembelajaran terpadu diawali dengan penentuan tema. Tema yang dipilih sebaiknya menghubungkaitkan antara IPA-lingkungan-teknologi-masyarakat.

Melalui pembelajaran IPA terpadu beberapa konsep yang relevan dapat dijadikan suatu tema tidak perlu dibahas berulang kali dalam bidang kajian yang berbeda, sehingga penggunaan waktu untuk pembahasannya lebih efisien dan pencapaian tujuan pembelajaran juga diharapkan akan lebih efektif. Untuk itu, dalam pembelajaran IPA terpadu dapat dilakukan dengan dua cara, yakni team teaching dan guru tunggal (Tim Widyaiswara LPMP Jawa Tengah, 2008). Peraturan Pemerintah No. 39 tahun 2009 merekomendasikan bahwa pelaksanaan pembelajaran IPA terpadu dilaksanakan dengan team teaching. Hal tersebut disesuaikan dengan keadaan guru dan kebijakan sekolah masing-masing dalam mencermati dan mengelola.

Pembelajaran IPA terpadu menurut Trianto (2007) meliputi tiga model yaitu model keterpaduan (integrated), model jaring laba-laba (webbed) dan model keterhubungan (connected). Model keterpaduan pada materi IPA tampak seperti pada bagan 1.

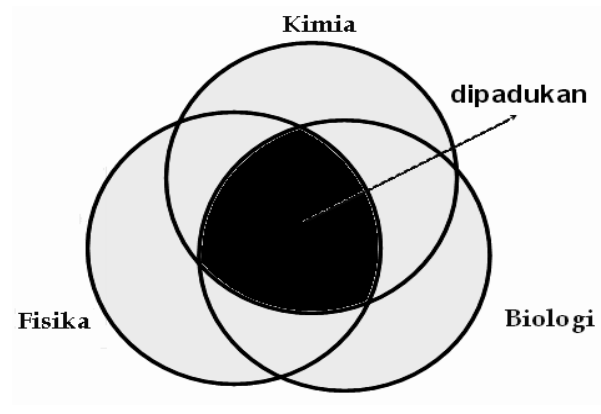

\section{Bagan 1. Model Keterpaduan Integrated}

Dalam model keterpaduan integrated, dimulai dengan identifikasi konsep, keterampilan, sikap yang overlap pada beberapa disiplin ilmu atau beberapa bidang studi. Tema berfungsi sebagai konteks pembelajaran. Dalam hal ini pelajaran dipusatkan pada satu masalah atau topik tertentu, dimana semua masalah pada mata pelajaran dirancang 
dengan mengacu pada topik tertentu pula. Di bidang ilmu alam integrasi dilakukan dengan mentautkan antara dua tema dalam Fisika, dan Biologi atau dalam tema Kimia dan Biologi yang memiki relevansi. Model keterpaduan integrated memiliki karakteristik membelajarkan beberapa kompetensi dasar yang konsep-konsepnya beririsan.

\section{Kelebihan Model Keterpaduan}

Kelebihan dan manfaat model integrated antara lain (Trianto, 2010): (a) Adanya kemungkinan pemahaman antar bidang studi, karena dengan memfokuskan pada isi pelajaran, strategi berfikir keterampilan sosial dan ide-ide penemuan lain, satu pelajaran dapat mencakup banyak dimensi, sehingga siswa, pembelajaran menjadi semakin diperkaya dan berkembang, (b) Memotivasi siswa dalam belajar, (c) Tipe terintegrasi juga memberikan perhatian pada berbagai bidang yang penting dalam satu saat, tipe ini tidak memerlukan penambahan waktu untuk bekerja dengan guru lain. Dalam tipe ini, guru tidak perlu mengulang kembali materi yang tumpang tindih, sehingga tercapailah efisiensi dan efektivitas pembelajaran.

\section{Kekurangan Model Keterpaduan}

Selain kelebihan yang dikemukakan di atas Trianto (2010) mengemukaan keterpaduan integrated memilki kekurangan antara lain: (a) Terletak pada guru, yaitu guru harus menguasai konsep, sikap dan keterampilan yang diperioritaskan, (b) Penerapannya, yakni sulitnya menerapkan tipe ini secara penuh, (c) Tipe ini memerlukan tim antar bidang studi, baik dalam perencanaanya maupun pelaksanaannya, (d) Pengintegrasian kurikulum dengan konsep-konsep dari masing-masing bidang studi menuntut adanya sumber belajar yang beraneka ragam.

\section{Pelatihan Sebagai Solusi dalam Pembelajaran IPA Terpadu}

Pelatihan merupakan salah satu program yang dapat dijadikan untuk mempertajam pengetahuan dan keterampilan bagi dosen. Program pelatihan diadakan dengan memfasilitasi dosen untuk peningkatan kualitas pengetahuannya agar output yang dihasilkan dalam lembaga pendidikan dapat memenuhi tuntutan stakeholder baik regional, nasional maupun internasional. Definisi Pelatihan menurut Agus M. Hardjana (2001) adalah kegiatan yang dirancang untuk meningkatkan kinerja pekerja dalam pekerjaan yang diserahkan kepada mereka. Sedangkan definisi pelatihan menurut Mustofa Kamil ${ }^{2}$ pelatihan sebagai proses pemberdayaan dan pembelajaran, artinya individu harus mempelajari materi guna meningkatkan kemampuan, keterampilan dan tingkah laku dalam

2 Mustofa Kamil, Model Pendidikan dan Pelatihan (Konsep dan Aplikasi), (Bandung: Alfabeta, 2010), hlm. 
pekerjaan dan kehidupan sehari-hari dalam menopang ekonominya (pendapatan). Menurut Simamora (1995) dalam Mustofa Kamil ${ }^{3}$ mengartikan pelatihan sebagai serangkaian aktivitas yang dirancang untuk meningkatkan keahlian-keahlian, pengetahuan, pengalaman, ataupun perubahan sikap seorang individu.

Sumber Daya Manusia di perguruan tinggi khususnya dosen memerlukan pengembangan khususnya pelatihan. Pelatihan merupakan upaya pengembangan diri bagi seorang dosen. Menurut Sedarmayanti (2010) bahwa ditinjau dari masa pelaksanaannya, pelatihan sebagai bagian dari tugas pengembangan dapat dibedakan menjadi tiga, yaitu: (a) Pre-service training (pelatihan pra-tugas) adalah pelatihan yang diberikan kepada calon karyawan yang akan mulai bekerja, atau karyawan baru yang bersifat pembekalan, agar mereka dapat melaksanakan tugas yang nantinya dibebankan kepada mereka. (b) In service training (pelatihan dalam tugas) adalah pelatihan dalam tugas yang dilakukan untuk karyawan yang sedang bertugas dalam organisasi dengan tujuan meningkatkan kemampuan dalam melaksanakan pekerjaan. (c) Post service training (pelatihan purna/ pasca tugas) adalah pelatihan yang dilaksanakan organisasi untuk membantu dan mempersiapkan karyawan dalam menghadapi pensiun, misalnya: pelatihan wirausaha, pelatihan peternakan.

Pelatihan IPA terpadu penyampaian materi, strategi pembelajaran dapat dicapai secara terpadu. Pembelajaran IPA terpadu akan lebih bermakna jika disertai dengan alat bantu, media dan metode yang kreatif dan inovatif. Pelatihan Pembelajaran IPA Terpadu pada Program PGMI merupakan solusi untuk memaksimalkan kemampuan dosen IPA yang berlatar belakang pendidikan sarjana pendidikan Biologi, Kimia dan Fisika serta Biologi murni, Kimia murni dan Fisika murni. Pelatihan IPA terpadu untuk meningkatkan professional dosen IPA prodi PGMI dapat dilaksanakan dengan menggunakan 2 (dua) model yaitu: (1) model acuan buku pedoman pelatihan IPA terpadu dengan pendampingan pakar IPA, dan (2) model pelatihan, silabus, RPP.

\section{E. Kesimpulan}

Pembelajaran IPA terpadu merupakan model implementasi kurikulum, yang mencoba memadukan beberapa kompetensi dasar yang dikemas dan disajikan dalam satu kegiatan pembelajaran dalam suatu topik/tema tertentu. Pembelajaran IPA terpadu memerlukan pengetahuan, strategi, media dan keterampilan bagi dosen dan guru. Pelatihan pembelajaran IPA terpadu pada dosen program PGMI merupakan solusi untuk memaksimalkan kemampuan dosen IPA yang berlatar belakang pendidikan sarjana pendidikan Biologi, Kimia dan Fisika serta Biologi murni, Kimia murni dan Fisika murni.

\footnotetext{
${ }^{3} \mathrm{Ibid}, \mathrm{hlm} .4$
} 
Pelatihan IPA terpadu untuk meningkatkan professional dosen IPA prodi PGMI dapat dilaksanakan dengan menggunakan 2 (dua) model yaitu: (1) model acuan buku pedoman pelatihan IPA terpadu dengan pendampingan pakar IPA, dan (2) model pelatihan, silabus, RPP. 


\section{DAFTAR PUSTAKA}

Agus M. Hardjana, Training SDM yang Efektif, Yogyakarta: Kanisius Press, 2001.

Barakat, Mohammad 'Adil (et. al.), al-Tathwir al-Mahniy li A'dla'i Hay'at al-Tadris, Tunis: alMunazhzhamah al-'Arabiyah li al-Tarbiyah, 1998.

Bundu, IP, Penilaian Keterampilan Proses dan Sikap Ilmiah, Jakarta: Depdiknas, 2006.

Depdiknas. Puskur Balitbang, Model Pengembangan Silabus Mata Pelajaran dan Rencana Pelaksanaan Pembelajaran IPA Terpadu, Jakarta, 2004.

Depdiknas. Pedoman Khusus Pengembangan Silabus IPA Terpadu Kurikulum Berbasis Kompetensi untuk SMP, Jakarta, 2004b.

Mustofa Kamil, Model Pendidikan dan Pelatihan (Konsep dan Aplikasi), Bandung: Alfabeta, 2010.

Sedarmayanti, Manajemen Sumber Daya Manusia Reformasi Birokrasi dan Manajemen Pegawai Negeri Sipil, Bandung: Refika Aditama, 2010.

Trianto, M.Pd., Model Pembelajaran Terpadu Konsep, Strategi, dan Implementasinya dalam Kurikulum Tingkat Satuan Pendidikan (KTSP), Jakarta: Bumi Aksara, 2010.

Tim Widyaiswara LPMP Jawa Tengah, Lesson Study, Semarang, 2008.

Trianto, Model Pembelajaran IPA Terpadu dalam Teori dan Praktek, Jakarta: Prestasi Pustaka Publisher, 2007.

Trianto, Mengembangkan Model Pembelajaran Tematik, Jakarta: Prestasi Pustaka, 2010. 
